Revista Brasileira de Informática na Educação - RBIE Brazilian Journal of Computers in Education (ISSN online: 2317-6121; print: 1414-5685) http://br-ie.org/pub/index.php/rbie

Submission: 16/Feb/2021;

Camera ready: 01/Oct/2021; $1^{\text {st }}$ round notif.: $19 / \mathrm{Jun} / 2021$;

Edition review: 25/Oct/2021;
New version: 18/Aug/2021; Available online: 17/Nov/2021; $2^{\text {nd }}$ round notif.: 18/Sep/2021; Published: 17/Nov/2021;

\title{
Computational Thinking for Youth and Adults Education: model, principles, activities and lessons learned
}

Júlia dos Santos Bathke Ortiz

Federal University of Paraná (UFPR)

Curitiba, Brazil

jubathke@gmail.com

\author{
Roberto Pereira \\ Federal University of Paraná (UFPR) \\ Curitiba, Brazil \\ rpereira@inf.ufpr.br
}

\begin{abstract}
Computational Thinking (CT) is considered one of the most needed abilities of the 21 st Century as the usage of digital resources has become more and more frequent. Research on CT teaching has been growing over the last decade and Brazilian initiatives have focused on Elementary and High School students while less privileged audiences, such as non-literate citizens, are rarely addressed. The lack of literacy affects more than communication, but autonomy for economic, cultural and educational development, social interaction, and also the experience with information and communication technology. Non-literate citizens represent more than 11 million people in Brazil, and Youth and Adults Education (YAE) is an educational modality offered to these citizens. In this article, we present the main results from a Master's research that investigated CT as a means to reduce YAE's students' rejection and fear of technology, aware of their characteristics, contexts, and particularities. In our research, we consider that through the practice of CT people can comprehend how technology works and how it can be used, favoring familiarity, and reducing rejection and fear of technology. Grounded on Computing and Education literature, we conceived a model to plan and conduct initiatives for YAE, applying and studying our model in a case study conducted inside a Brazilian public school during 8 workshops with 17 participants. For the case study, 9 principles to support the practice with YAE students were identified and used to inform 12 activities created/adapted for practicing CT throughout the workshops. A research overview is presented, along with its theoretical grounds to the main results from the case study and lessons learned. Results show the model as promising to inform practices to exercise CT abilities, sensitive to the audience's context. Keywords: Computational Thinking; Informatics in Education; Digital Culture; Digital Divide; Digital Inclusion.
\end{abstract}

Cite as: Ortiz, J. S. B., \& Pereira, R. (2021). Computational Thinking for Youth and Adults Education: model, principles, activities and lessons learned. Revista Brasileira de Informática na Educação, 29, 1312-1336. DOI: $10.5753 /$ rbie.2021.2338. 


\section{Introduction}

Computational Thinking (CT) is the ability of using Computer Science concepts and techniques to solve problems from different fields. CT has received growing attention in academic literature as studies have reported initiatives to develop it with different audiences. Researchers around the world have argued that CT benefits not only computer scientists but everyone (Wing, 2006; Nardelli, 2019; Tissenbaum, Sheldon, \& Abelson, 2019). However, in a systematic mapping review covering ten years of initiatives to promote computational thinking, the vast majority of the mapped studies had focused on children and teenagers, and few studies addressed adult students, especially those in digital and social vulnerability (Ortiz \& Pereira, 2019b) such as students of Youth and Adults Education ${ }^{1}$ (YAE).

In 2019, approximately $6.6 \%$ of the Brazilian population over 15 years were unable to read or write ${ }^{2}$, a condition that strengthens barriers for digital, social, economic, and educational access and development. The YAE is the modality for people who have not completed Elementary and High School at the expected age. Among several reasons why students leave school, the need to start working to financially assist their families is the main one (Neri, 2009). YAE audience has unique characteristics, social and cultural contexts, barriers, necessities, and expectations, all hampered by the lack of education. For YAE students, before the issue of using technology, there are socio-cultural-economic challenges that prevent them from accessing technology. Such a challenge appears in the United Nations' Sustainable Development Goal \#4 ${ }^{3}$, which is dedicated to gathering forces to ensure inclusive and equitable quality education, promoting lifelong learning opportunities for all, particularly for marginalized and vulnerable people.

If for children and teenagers CT represents important abilities to live in a digital age, for people in situations of social and digital exclusion, developing these skills is a matter of inclusion, identity and existence for the exercise of citizenship. To the best of our knowledge, only two research have investigated CT in the YAE context: Costa (2014) and Ortiz \& Raabe (2016). However, a systematic literature mapping found no material to support the design, planning, and conduction of initiatives to practice CT with YAE students (Ortiz \& Pereira, 2019b).

Giving the gap in the literature, this article presents the main results from a research ${ }^{4}$ that addressed the lack of knowledge to support the design, planning, and conduction of initiatives to develop CT with YAE students. Contributing to advance the knowledge body, we outline a Socially Aware Model for practicing CT, designed to support the understanding and conduction of initiatives sensible to YAE students' socio-cultural context and particularities, understanding CT abilities as promising to promote digital inclusion and, therefore, actually useful for everyone.

The goals of this research were: to propose a model for supporting CT initiatives with YAE students; to conduct studies in real settings; to investigate the model effectiveness (if it meets the objectives for which it was proposed); to document the model and activities developed for its

\footnotetext{
${ }^{1}$ Translated from the Portuguese: Educação de Jovens e Adultos.

${ }^{2}$ According to data available in https://www.ibge.gov.br/indicadores.html, last access on August 17th, 2021.

${ }^{3}$ Available at https://sustainabledevelopment.un.org/sdg4 last access on August 17th, 2021.

${ }^{4}$ This article summarizes the main results from the first author's Master's research (Ortiz, 2019), defended at the Federal University of Paraná (UFPR), and presents an extended and revised version of the paper (Ortiz \& Pereira, 2020) published and awarded in the "Alexandre Direne Contest of Dissertations in Computers in Education (CTD-IE) 2020", promoted by the Special Committee of Computers in Education of the Brazilian Computer Society.
} 
application and their observed outcomes; to analyze and document lessons learned, and to share the results obtained throughout this research to support further initiatives for YAE audience.

From a conceptual perspective, the main original aspect of this research is approaching CT as a way to promote familiarity with technology and, then, foster digital inclusion. Concepts such as abstraction, algorithms, problem decomposition, and pattern recognition have the potential to enhance students' comprehension, use, and appropriation of technology. This understanding, aligned with the practice of $\mathrm{CT}$ abilities, has the potential to enable an autonomous and positive experience when using technology. The more people practice, the more they understand, and the more autonomous and confident they get, in a cycle of continuous reinforcement.

The Socially Aware Model was created adopting constructive and applied research and was inspired by the literature on education and computing. Different resources informed the model, and different practices support its application. The model was constructively applied during 8 workshops in a case study situated in a public school. Evaluation methods used were voting and feedback from students, structured observation from researchers, and unstructured interviews with YAE teachers. Results show the model as promising to support researchers when conceiving and conducting CT practices with YAE students. The model has helped us to understand our audience and propose and conduct activities that kept them engaged and interested, moving from students' feelings of fear and inadequacy to an increasing sense of self-confidence and interest to learn more about technology.

For the case study, 12 different activities were produced and conducted resulting in 17 lessons learned that may inspire or support other initiatives designed for the YAE modality. These contributions are available online $e^{5}$ for the public and have been published or are under review in different papers.

This article presents the theoretical grounds of the Socially Aware Model in Section 2, and the research methodology in Section 3. The model is presented in Section 4. An overview of the case study is described in Section 5, along with a brief description of how the model steps were conducted to design the workshops. Section 6 presents the results and discussion from the case study. Finally, Section 7 summarizes the lessons learned that may be useful to guide initiatives with the YAE audience.

\section{Theoretical Grounds}

This research draws on authors from different fields. The works from Freire (1997) and Vieira Pinto (2013) provided a greater understanding of teaching adults, especially for vulnerable settings. CT's technical aspects are provided by Barr \& Stephenson (2011), Tissembaum et al. (2019), Nardelli (2019), and, Raabe et al. (2018). Finally, the understanding of a socially aware initiative comes from Baranauskas' (2014) Socially Aware Design.

\footnotetext{
${ }^{5}$ Available at: https://web.inf.ufpr.br/ihc/2021/08/03/msc-pc-eja/ last access on August 17th, 2021.
} 


\subsection{Computational Thinking}

Since Wing's seminal paper (Wing, 2006), more and more researchers have started to discuss CT as one of the 21's century abilities, and different definitions have aroused. According to Nardelli (2019), Computational Thinking is the thought process involved in modeling a situation and specifying how an agent can effectively operate within this situation, aiming to achieve specific goals. To Li et al. (2020), Computational Thinking is more about thinking than computing; it is more about knowing how to collect, interpret, and manipulate information than computing it - in the same way as mechanical thinking is more than just knowing how to drive a car. Several authors also cite different skills related to Computational Thinking. The set of skills we considered for this research are: data collection, data analysis, data representation, pattern recognition, problem decomposition, abstraction, algorithms and procedures, automation, parallelism, and simulation, according to Barr \& Stephenson (2011).

As CT become popular, several initiatives to teach this ability have been conducted. However, according to Tissenbaum et al. (2019), many initiatives have failed to connect to specific personal interests and lives of learners, making them feel this ability is not relevant for them to learn. Claiming for the need to move from computational thinking to computational action, the authors claim that while learning about computing, people must be engaged in experiences that directly impact their lives and their communities. Therefore, we must situate activities in real-world contexts that matter to students.

\subsection{Socially Aware Model}

The Socially Aware Design (SAwD) model guides the design and conception of interactive computing technology with social responsibility in a participatory way (Baranauskas, 2014). To exemplify the SAwD model's philosophy, consider the following scenario: when people have a health problem and seek treatment, it is expected that before doctors give any prescription or recommendation, they listen to their patients and investigate what the real problems are, so they can further determine what could or could not work for each patient, and are able to explain what the implications of each kind of treatment are so, together, they (doctors and patients - and possibly other interested parties) could find a proper solution for the patients' problems.

In a very simplified way, this is the idea SAwD defends and supports for interactive computing technology design: before designing any kind of solution, the model suggests an understanding of the problem, involving possible users and different stakeholders (i.e., interested parties) that are or will be directly affected by the problem or by a prospective solution, and to analyze the problem context in different dimensions. That is why SAwD is a socially aware and responsible model: it focuses on understanding the problem before anything else; the extension of this understanding goes beyond just technical aspects of the problem and covers informal (i.e., culture and values) and formal (i.e., rules and procedures) dimensions of the problem and context of use; and this investigation is conducted with the participation of those who are/will be impacted by the problem or its solution, resulting in a co-design where society impacts the design and design impacts back.

Bringing the SAwD model into the education context of this project means to promote a democratic space for the expression of opinions, curiosity, and necessities, resulting in addressing many subjects that actually matter to the participants. As the subjects come up through participa- 
tory practices with the group, it represents all the participants' preferences and context (whether they are regular students or teachers), thus engaging and enriching the learning experience. So, before determining what practices students will experience about technology, we focus, together, on the interests, needs, curiosities, doubts, or day-by-day problems that could be approached with the available technology. Then, we can design activities to accomplish these problems, situations, and so on, considering the abilities and experiences students already have.

SAwD has been applied in different scenarios and contexts, including educational ones (such as Nicastro, Baranauskas \& da Silva Torres, 2018; Carbajal \& Baranauskas, 2019; Panaggio, Carbajal \& Baranauskas, 2019; Moreira, Dos Reis \& Baranauskas, 2019; Mendoza \& Baranauskas, 2020). SAwD inspires this research with the premise of seeing students as creators of their own knowledge, and has the potential to methodologically inform the initiative in order to start with getting to know the participants and understand the different stakeholders involved in a given situation, their cultural and socioeconomic realities, their expectations, needs, values, and then use this information to design and conduct engaging activities to promote CT.

\section{Methodology}

The methodology for this research covered conceptual and applied investigations through: i) Pilot study, ii) Literature Review, and iii) Case Study. For the i) Pilot Study, a service project named "Programming my Context" was carried out with students between 12 and 29 years old (age range partially eligible for YAE) from a vulnerable neighborhood in Curitiba. Coordinated by Ermelindo Schultz, the project proposed 9 classes to teach CT skills while designing games on Scratch (Schultz, Ortiz, García, \& Pereira, 2018). The classes were designed to evolve from the stage of investigation to thematization, problematization, and construction, according to Freire's Method (Feitosa, 1999) and was inspired by Participatory Design (DiSalvo, Yip, Bonsignore, \& Carl, 2017). This project served as an exploratory case study for conceiving the model and for the authors' experience in planning and conducting contextualized and socially responsible activities due to its theoretical ground and addressing students in similar conditions to the YAE audience (age and in social vulnerability).

For the ii) Literature Review, a systematic mapping covering initiatives to develop CT identified papers published in both Brazilian and international digital databases between 2007-2017, since Wing's seminal paper on "Computational Thinking" (Ortiz \& Pereira, 2019b). From this systematic mapping, only 1 from 46 initiatives addressed adult students in social, economic, and digital vulnerability situations. The only one, conducted by Ortiz \& Raabe (2016), reveals challenges for working with the YAE public, especially regarding students' engagement. Results from the systematic mapping also revealed that only 5 of the 46 initiatives mentioned addressing social and cultural aspects of students' context (Ortiz, Moreira \& Pereira, 2019). As pointed out by Tissembaun et al. (2019), we could identify that the lack of connection from the activities to the real world negatively affected students' motivation and their perception of how thinking computationally could be useful for their lives.

Another research that involved the YAE audience and CT was conducted by Costa (2014). This one was not part of the literature review corpus because it was not available in the digital databases selected for the study. However, it is related to this research due to its audience and the 
promoted ability (CT). This initiative proposed an app to stimulate and practice CT among the YAE students, and a case study was conducted to evaluate aspects of this app, as if it was easy to use, if information and objects as buttons were easily perceived, among others. With only two initiatives with the YAE audience, it is safe to say that efforts are still needed to better comprehend and support CT initiatives in this context.

For the iii) Case Study, we conducted practical activities inside a Brazilian public school where CT was approached as a means to reduce YAE's students' rejection and fear of technology, potentially fostering digital inclusion and culture. Instead of focusing on teaching CT abilities, we embedded them into meaningful activities to promote contact with technologies and conducted them at 8 thematic workshops informed by our model and by its ongoing results.

For evaluating the case study, feedback from students, unstructured interview with teachers, and natural observation (Sparling \& Chong, 2011) by researchers were adopted as evaluation methods (Best \& Kahn, 2016). Before each workshop, planned activities were presented to YAE teachers who provided feedback and suggestions. During each workshop, at least one researcher was in charge of taking notes about students behavior, feedback, performance, etc. Notes were then shared and discussed among researchers to inform the next activities.

\section{Towards a Socially Aware Model}

Built on the background presented, the Socially Aware Model for promoting Computational Thinking initiatives for Youth and Adults Education offers three main steps, as Figure 1 shows.



Figure 1: Steps of the Socially Aware Model for CT initiatives with YAE audience.

Step 1 - get to know the students: Comprehend students' world view and understand what is relevant and useful to them to determine what technology to use and what contents and activities to explore involving CT abilities. This step must start an open and trustful working environment for all the participants. Important issues to identify are students' expectations, needs, knowledge, contents they are studying in the regular class, technologies they know or have access to, and the ones they would like to learn more about. Different techniques or strategies can be put into practice to raise this information in a positive, natural, and funny way (e.g., games and storytelling). The key point is to engage people in meaningful and positive experiences with technology usage, 
promoting well-being and a feeling that we are all learning together.

Step 2 - create activities: Combine all the information previously raised to determine the contents and technology to be addressed, and CT skills to be practiced in activities to engage students. Each activity must address relevant and useful issues students want to learn, and must explore possibilities with devices they may have access to, naturally exploring CT concepts and skills with them. New activities can be elaborated, or existing ones can be adapted, as long as they incorporate relevant aspects of students' context and follow the principles for practices with YAE students (see Section 4.1). Activities must be as universal as possible to attend the diversity of students. Defining activities to be conducted, outcomes to be evaluated, and elaborating the necessary materials to their conduction are also part of this step.

Step 3 - carry out activities: When putting activities into practice, be aware of important particularities of the YAE audience. This step also encompasses socialization and evaluation, which may occur in different ways according to the goal of each initiative (e.g., students' progress, what they have learned with the activity, their perception of technological devices usage, etc.).

Every workshop must be designed in this movement from Step 1 through Step 2, and Step 3. During the practice of activities in Step 3, new interests, doubts, and needs may arise and serve as input for a new cycle, creating an iterative and constructive movement. Our case study, presented in Section 5, allowed us to refined our Socially Aware Model while informing our practices with YAE students through its steps and principles.

\subsection{Nine Principles to Guide the Practice with YAE}

From the Pilot Study and the Literature Review, we identified 9 principles to guide the practice in YAE contexts (Ortiz \& Pereira, 2019a). These principles informed our model and the activities we created to mediate interaction with the participants in our case study. The case study and its results, in turn, allowed us to refined the principles and offered real examples of their application.

1. Socio-culturally Contextualized: activities must be as close as possible to the students' socio-cultural context. The content must make sense to the students' context so that the knowledge they are creating can be applied and related to their needs, interests, desires, curiosities, difficulties, etc. This principle requires investigating the mentioned aspects even if the team conducting the initiative already knows the students because "predicting" them based on what is already known about the students does not favor participation and can result in a biased activity.

2. Useful: activities must involve useful things for students, things they can use for some purpose in their daily lives, and, preferably, contents they could apply or use immediately. Because of YAE's characteristics and because students are trying to make up for the time they were out of school, the usefulness of the discussed topics must be clear for them, to favor the feeling that they are progressing and learning more.

3. Relevant \& Appropriate: activities must contemplate needs, expectations, and interests that matter to students - preferably, the most relevant situations for students should be considered in the activities. Also, activities must explore students' previous knowledge. However, because some polemic subjects could arise in their personal preferences, such as religion and politics, these issues must be approached carefully. 
4. Participatory: conduct activities stimulating everyone in the role of participants: we are practicing and learning together. Naturally, some participants play the role of mediator, but everyone should participate when practicing with the YAE (students, researchers, and teachers). It is a sign of respect and honor, as students have many life experiences to share too. When conducting activities with YAE students, participants should engage in all activities dynamically and responsibly. Be sure to encourage them to recognize themselves as capable and responsible for creating their own knowledge. When working in a participatory way, the topic addressed must consider aspects and experiences of all the participants, enriching the learning experience.

5. Universal: activities must be designed to account for differences, to be suitable for the most different levels of abilities found in the respective group of students. The same activity (with the same materials) must be applied for all the participants, especially concerning limitations or difficulties in terms of movement and vision. In cases of severe disabilities (such as deafness or blindness), and depending on the nature of the activity, some specialized resource may be necessary. However, the designed solution must be suitable for as many people as possible, avoiding segregating the participants.

6. Self-contained: due to the irregular attendance in the YAE, activities must be independent, starting and finishing in the same workshop. If students miss any activity, they may find no impediment to participating in the next ones. Even when activities are linked to the previous ones, a new student must be able to start participating.

7. Differentiated \& Attractive: the environment in which practical activities take place should be different from the conventional classroom style (lines of individual desks directed to the board) in order to stimulate creativity and participation. Formats in which students are arranged in a circle, divided into teams or other ways that favor direct contact, communication, and collaboration with each other are recommended. Activities should be presented in an inviting and attractive way to raise students' interest.

8. Trans-disciplinary: activities must involve a combination of different contents, prioritizing the work in thematic problem situations instead of specific contents. Because CT can be useful to solve different types of problems, being described as a trans-disciplinary ability, involving concepts of more than one subject enhances CT's potential. Therefore, students may see several examples to apply the learned skills.

9. Progressive: the complexity of activities and contents must evolve progressively. Students may need time to reflect on some content or practice, try, test, work on new hypotheses, and so on. When working with students of different profiles and ages, it is expected that they take different times to assimilate the contents. Their time should be respected: instead of speeding up students who have not finished their activities, offer additional activities for those who have already finished, ask them to help other students, or show what they have done and learned.

These nine principles must be kept in mind when working with YAE students. These principles influence how a prospective activity must be structured and its purpose, material, and method. Although these principles are not exhaustive or definitive, we understand them as a basic set of principles that must be considered when planning and conducting initiatives with the YAE. 


\section{Case Study in the Youth and Adults Education}

The Socially Aware Model for practicing Computational Thinking with YAE was applied to support context understanding and activities planning and conduction during the case study. This case study was part of a service project approved by the University and the School. All students were invited to attend the workshops, and their participation was voluntary. The informed consent form was orally obtained as students were in the literacy process. Table 1 presents details about the case study. For using the model, the goal was to investigate its applicability and capability to support us to reach students' context and get ideas and recommendations for its improvement. As a first result and positive evidence, the model helped us to define our main goal: promoting students' familiarity with contemporary technology. This goal was an adequate one, as we validated with YAE teachers that their students had strong barriers for contact with technology, especially personal barriers involving their feelings, self esteem, perception of their own capability and autonomy.

Table 1: Case Study technical details.

\begin{tabular}{|l|l|}
\hline Where? & $\begin{array}{l}\text { Rachel Mader Gonçalves school, a public school in a low-income neighbor- } \\
\text { hood of Curitiba, Brazil. }\end{array}$ \\
\hline How many workshops? & 8 workshops. \\
\hline How often? & 1 workshop per week. \\
\hline When it happened? & second semester of 2018. \\
\hline Workshops duration & approximately 2 hours each. \\
\hline $\begin{array}{l}\text { How many students? What } \\
\text { was the students age range? }\end{array}$ & $\begin{array}{l}\text { a total of } 17 \text { students. Average attendance was } 12 \text { students per workshop. } \\
\text { Ages from } 16 \text { to } 70 \text { years old. }\end{array}$ \\
\hline $\begin{array}{l}\text { How many researchers took } \\
\text { part on the initiative? }\end{array}$ & $\begin{array}{l}\text { (researchers: the first author (the main facilitator) and the second author } \\
\text { (observer and participant), and Deógenes Pereira Jr. and Carolina M. Oliveira, } \\
\text { from the IHC-UFPR research lab (observers and participants). }\end{array}$ \\
\hline $\begin{array}{l}\text { How many YAE teachers par- } \\
\text { ticipated? }\end{array}$ & 2 YAE teachers. \\
\hline Evaluation methods used & $\begin{array}{l}\text { voting and feedback from students, structured observation from researchers, } \\
\text { and unstructured interviews with YAE teachers. }\end{array}$ \\
\hline
\end{tabular}

The case study was initially planned as a season of 4 episodes (workshops). If our audience (students and teachers) wanted more, we would extend the season by adding extra episodes. Due to positive feedback and requests from both students and teachers, episodes were extended from 4 to 8 , reaching the end of the term. We consider this extension as another positive evidence that, inspired by our model, we were able to offer workshops that were well accepted and positive for them. Table 2 presents an overview of the 8 workshops, with their title, goals, CT abilities involved, and a brief of their outputs.

The TV Series metaphor was adopted following the idea that a story is composed of small pieces of stories - accomplishments by each student - how their familiarity with technology is expected to happen. Even if two episodes are similar, in the major story they would never rewrite one another. Even if we use the same activity in two different workshops, they will never have the same results because the timing would be different, the student's abilities, experiences, and their knowledge level would be different. Continuing the story is determined by our audience: if students are engaged in practicing and want to keep learning about technology, new workshops can be designed, and new seasons can be produced. 
Table 2: Overview of 8 the workshops conducted at Rachel Mader Gonçalves school.

\begin{tabular}{|c|c|c|}
\hline Title and Goal & CT abilities involved and examples & Outcomes \\
\hline $\begin{array}{l}\text { 1: The icebreaker. Introduce } \\
\text { the study and its goals, get to } \\
\text { know the students, understand } \\
\text { their context and discuss about } \\
\text { technologies in a StoryTelling } \\
\text { style. }\end{array}$ & $\begin{array}{l}\text { Pattern recognition and abstraction. } \\
\text { Pattern recognition: to distinguish } \\
\text { electrical and technological devices. }\end{array}$ & $\begin{array}{l}\text { Informed the following workshops and } \\
\text { promoted the feeling of belonging to a } \\
\text { group that everyone had possibilities and } \\
\text { limitations, and what to learn and teach. } \\
\text { Students' interest about technology were: } \\
\text { smartphones, music, making calls, taking } \\
\text { pictures and using ATMs. }\end{array}$ \\
\hline $\begin{array}{l}\text { 2: Training family photog- } \\
\text { raphers. Discuss about pho- } \\
\text { tos, describe and perform a se- } \\
\text { quence of steps to take pictures } \\
\text { using different devices. }\end{array}$ & $\begin{array}{l}\text { Algorithms, pattern recognition and } \\
\text { automation. Algorithm: when creat- } \\
\text { ing a sequence of steps to achieve a } \\
\text { goal (i.e., taking a nice picture con- } \\
\text { sidering its framing and lighting). }\end{array}$ & $\begin{array}{l}\text { Explored the connection between home, } \\
\text { personal life and school, creating oppor- } \\
\text { tunities for them to show and practice at } \\
\text { home what they were exploring in the } \\
\text { classroom. }\end{array}$ \\
\hline $\begin{array}{l}\text { 3: Let's talk about voting. } \\
\text { Discuss about the voting ter- } \\
\text { minal, describe and execute a } \\
\text { sequence of steps to vote. }\end{array}$ & $\begin{array}{l}\text { Problem-decomposition, algorithms, } \\
\text { simulation and pattern recognition. } \\
\text { Algorithm: voting for different can- } \\
\text { didates until the process was finished, } \\
\text { and deciding whether the correct can- } \\
\text { didate was selected according to the } \\
\text { entered number. }\end{array}$ & $\begin{array}{l}\text { Aligned with the } 2018 \text { election scenario, } \\
\text { the exercise of citizenship was discussed } \\
\text { by involving the voting terminal, an im- } \\
\text { portant device that still caused anxiety and } \\
\text { was challenging for them. }\end{array}$ \\
\hline $\begin{array}{l}\text { 4: Searching on YouTube. } \\
\text { Introduce YouTube and the } \\
\text { voice-based interaction. Per- } \\
\text { form a sequence of steps to } \\
\text { search. }\end{array}$ & $\begin{array}{l}\text { Algorithms, automation, pattern } \\
\text { recognition and simulation. Automa- } \\
\text { tion: share a sequence of steps and } \\
\text { process it on multiple devices. }\end{array}$ & $\begin{array}{l}\text { Involved them in using voice-based com- } \\
\text { mands, exploring new forms of interac- } \\
\text { tion and new applications through positive } \\
\text { and valuable experiences for their lives, } \\
\text { searching for recipes and songs they liked. }\end{array}$ \\
\hline $\begin{array}{l}\text { 5: Game night! Play a game } \\
\text { and remember what have been } \\
\text { seen regarding technology so } \\
\text { far. }\end{array}$ & $\begin{array}{l}\text { Algorithms, problem decomposition, } \\
\text { data analysis and pattern recognition. } \\
\text { Problem decomposition: in splitting } \\
\text { the 'winning the game' goal into } \\
\text { smaller achievements. }\end{array}$ & $\begin{array}{l}\text { Fully integration with the literacy content } \\
\text { that teachers worked with them, in which } \\
\text { they could see more clearly their progress } \\
\text { while enjoying a YouTube soundtrack } \\
\text { they had created in the previous workshop. }\end{array}$ \\
\hline $\begin{array}{l}\text { 6: Lady Miroca: movie and } \\
\text { popcorn. Watch a movie that } \\
\text { presents an algorithm created } \\
\text { and executed by someone with } \\
\text { similar characteristics to the } \\
\text { students, and discuss it. }\end{array}$ & $\begin{array}{l}\text { Algorithms, simulation, data analysis } \\
\text { and pattern recognition. Data anal- } \\
\text { ysis: in analyzing words that rhyme } \\
\text { (the main character of the movie used } \\
\text { to speak only through rhymes). }\end{array}$ & $\begin{array}{l}\text { Film session, part of school's official pro- } \\
\text { gram, indicating workshops were con- } \\
\text { nected with other events in school life. } \\
\text { Also showed a connection with what they } \\
\text { had been learning and producing in the } \\
\text { previous workshops. }\end{array}$ \\
\hline $\begin{array}{l}\text { 7: Hello? Who is this? In- } \\
\text { troduce WhatsApp audio and } \\
\text { video calls. Build and perform } \\
\text { a sequence of steps to make a } \\
\text { call. }\end{array}$ & $\begin{array}{l}\text { Algorithms, pattern recognition, data } \\
\text { analysis, automation and simulation. } \\
\text { Simulation: in practicing with low fi- } \\
\text { delity materials before practicing in a } \\
\text { real device. }\end{array}$ & $\begin{array}{l}\text { They have put all their skills into practice, } \\
\text { both in terms of contact with technology } \\
\text { and in terms of didactic content worked, } \\
\text { showing confidence and familiarity with } \\
\text { the activities. }\end{array}$ \\
\hline $\begin{array}{l}\text { 8: The Grand Finale. Re- } \\
\text { member all workshops, talk } \\
\text { about the initiative and get } \\
\text { feedback from students about } \\
\text { the classes for a further season } \\
\text { with more workshops. }\end{array}$ & - & $\begin{array}{l}\text { The socialization and the remembrance of } \\
\text { all the way through the season brought the } \\
\text { feedback on what was worked and what } \\
\text { could be even better, resulting in the re- } \\
\text { newal of the partnership for a new season. }\end{array}$ \\
\hline
\end{tabular}

A set of 12 activities were created through the model for the YAE public and are presented in Table 3. A catalog with these activities along with other materials of the research are available 
online $^{6}$ (in Portuguese only) and can serve as inspiration or starting point to other initiatives.

Table 3: Set of activities created for the Case Study.

\begin{tabular}{|c|c|c|c|}
\hline \# & Name & Goal & Workshop \\
\hline 01 & StoryTell-me & $\begin{array}{l}\text { Share experiences about technology to get to know one an- } \\
\text { other. }\end{array}$ & Workshop 1. \\
\hline 02 & $\begin{array}{l}\text { Conversation about tech- } \\
\text { nology }\end{array}$ & $\begin{array}{l}\text { To get to know students perception about specific technolo- } \\
\text { gies. }\end{array}$ & Workshop 1. \\
\hline 03 & $\begin{array}{l}\text { Voting with colored } \\
\text { cards }\end{array}$ & $\begin{array}{l}\text { To get feedback from the students about their interest in } \\
\text { continue to attend the workshops. }\end{array}$ & $\begin{array}{l}\text { Workshop } 1, \\
2 \text { and } 8 .\end{array}$ \\
\hline 04 & Training photographers & $\begin{array}{l}\text { Create and execute a sequence of steps about how to take } \\
\text { pictures on smartphones. }\end{array}$ & Workshop 2. \\
\hline 05 & Voting with emoji cards & $\begin{array}{l}\text { To get feedback from the students about their learning self- } \\
\text { perception. }\end{array}$ & Workshop 2. \\
\hline 06 & $\begin{array}{l}\text { Practice voting on a vot- } \\
\text { ing terminal prototype }\end{array}$ & $\begin{array}{l}\text { Create and execute a sequence of steps about how to vote } \\
\text { on voting terminals. }\end{array}$ & Workshop 3. \\
\hline 07 & $\begin{array}{l}\text { Voting with colored } \\
\text { cards and cards with } \\
\text { emojis }\end{array}$ & $\begin{array}{l}\text { To get feedback from students about their interest to keep } \\
\text { learning about technology, and about their learning self- } \\
\text { perception. }\end{array}$ & $\begin{array}{l}\text { Workshops } 3 \text {, } \\
4,5,6 \text { and } 7 .\end{array}$ \\
\hline 08 & $\begin{array}{l}\text { Voice command search } \\
\text { on YouTube }\end{array}$ & $\begin{array}{l}\text { Create a sequence of steps about how to search through } \\
\text { voice command on YouTube. }\end{array}$ & Workshop 4. \\
\hline 09 & Remind me game & Practice all the sequences of steps we have created so far. & Workshop 5. \\
\hline 10 & Rhyming in timing & Create an algorithm to identify and propose rhymes. & Workshop 6. \\
\hline 11 & Making phone calls & Interpret and execute a sequence of steps to make a call. & Workshop 7. \\
\hline 12 & $\begin{array}{l}\text { Ordering sequences of } \\
\text { steps }\end{array}$ & $\begin{array}{l}\text { Ordering a sequence of steps to make calls, take pictures } \\
\text { and search through voice command. }\end{array}$ & Extra activity. \\
\hline
\end{tabular}

Because the initiative's main goal involved students' perceptions about themselves (their capacity and self esteem), their opinion about their own progress and their interest in the activities would give us the most trustworthy evidence. More important than reaching a specific performance or grade is whether students felt they were learning and wanted to keep learning. Observations from researchers and interviews with teachers would provide additional evidence about whether we were succeeding in reaching students' context and becoming part of it. Therefore, free feedback from students, unstructured interview with teachers, and natural observation (Sparling \& Chong, 2011) by researchers were adopted as evaluation methods in this case study (Best \& Kahn, 2016).

At the end of each workshop, students were asked to answer 2 questions by using colored cards and cards with emojis and put them into a ballot box. For identifying students' engagement, the first question was: "Do I want to keep learning about technology?", and for identifying their learning self-perception, the second question was: "How much do I think I have learned from this workshop?". Figure 2 presents details about the possible answers for these questions. Voting was optional and anonymous as the ballot box was placed outside the classroom. Teachers and researchers also registered explicit feedback from the participants. For the final workshop, a video $^{7}$ was produced with several pictures taken during the former workshops.

\footnotetext{
${ }^{6}$ Available at: https://web.inf.ufpr.br/ihc/2021/08/03/msc-pc-eja/ last access on August 17th, 2021.

${ }^{7}$ The video is available at https://www.youtube.com/watch?v=fIv_2XsugQ4 last access on August 17th, 2021.
} 


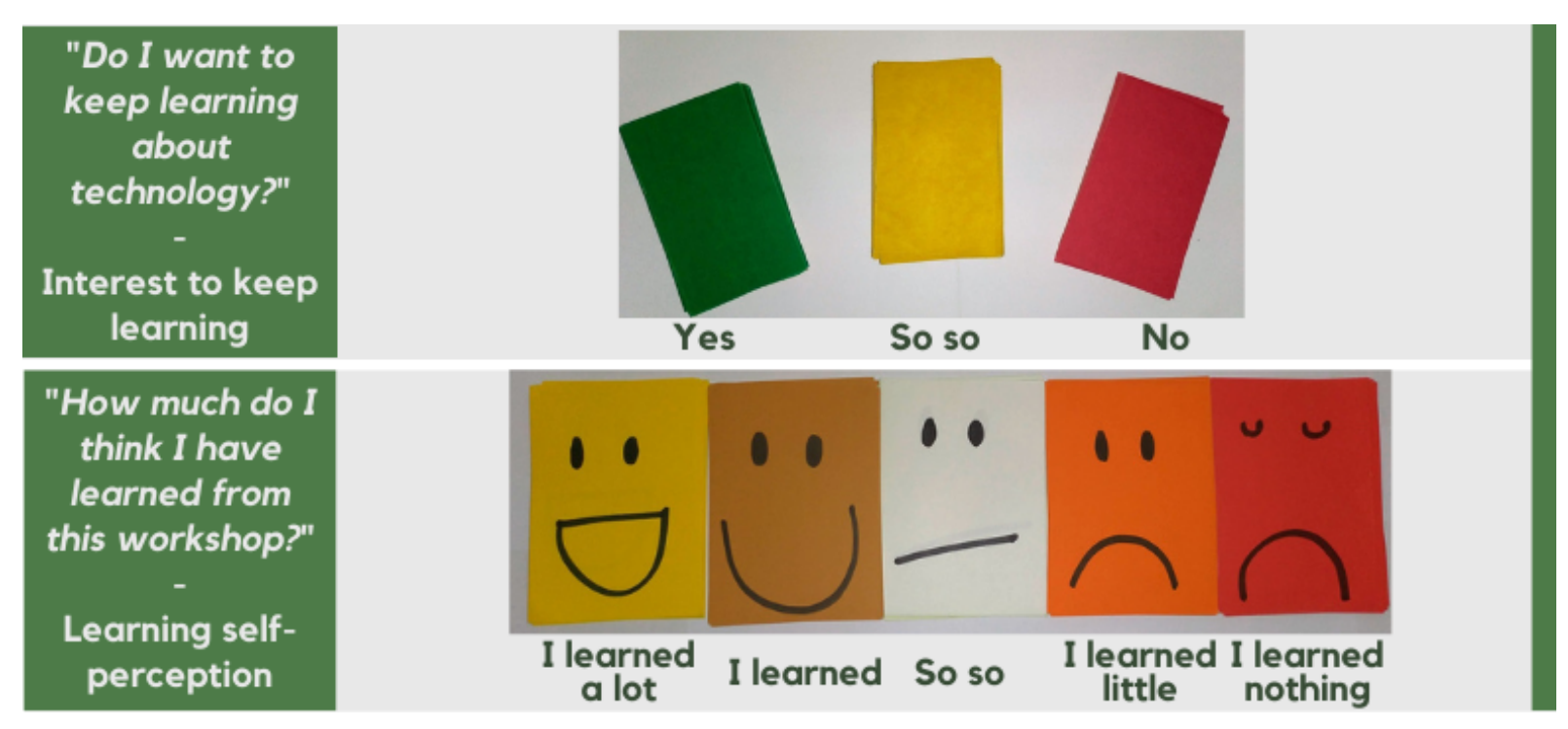

Figure 2: Questions asked to students and the possible answers.

\subsection{The Socially Aware Model in practice}

A description of how the model's steps were conducted to design workshops and activities is presented here to illustrate the model in action. Two cycles of model steps and two activities are presented with the materials involved. Pictures from the workshops illustrate their application in the case study.

Step 1 - get to know the students: The Step 1 for the very first cycle started when we visited the school to meet the school's principal and the YAE teachers, presenting our proposal for the initiative and receiving information regarding the students, their preferences, life conditions, motivation, etc. We received feedback from teachers about our proposal and then we produced the activities for the first workshop.

In the first workshop, we had the opportunity to get to know the students, talk and interact with them and the YAE teachers, and set a friendly and trustworthy feeling about the moment. The goal was to better understand their needs and opportunities regarding technology. After personal introductions, the workshop started with a moment to all the participants (researchers, students, teachers, everyone that attended the class) share their experiences about technology. We asked them to point out some issues with technology, such as the more used ones (by each one), the ones they had access to, the ones they would like to learn more about, the ones they knew the purpose of usage, the ones they could not use before, etc. We designed an activity (Activity 01 in Table 3, inspired by Schultz et al. 2018) to make this conversation more interesting and to help establishing an order of who would be the next to speak. For the following moment, we used Activity 02, described as follows.

Activity 02 - Conversation about technology: for this activity, we took 8 cardboards in different colors. In each cardboard, we put a different technology (name and image that represent it), as: smartphone and ATM. We prepared small cards of the same colors of the cardboards (Figure 3). So, for each cardboard, we asked students what that technology is, its function, and so on. When we finished talking about the technologies, we asked students to choose 3 technologies 
they would like to learn about, taking the correspondent cards among the options and putting them into a ballot box.

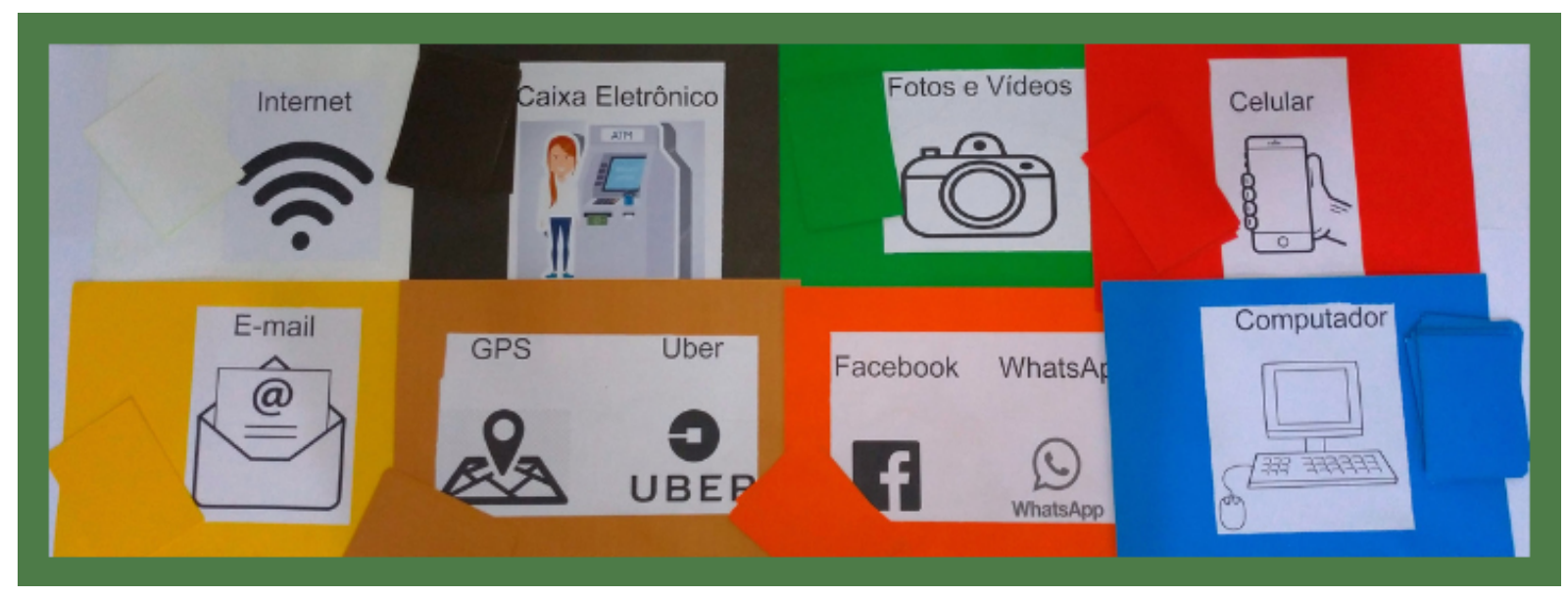

Figure 3: Cardboard in 8 different colors, with 8 different technologies, and with small cards of the same colors.

In this activity, the Socio-culturally contextualized principle informed the activity design and goal: to get to know the students. The Relevant \& Appropriate principle was considered by selecting 8 technologies the teachers informed they were close to and bringing them to the discussion. The Universal principle was traduced by the material chosen for the activity: cardboards are easy to manipulate and adapt. When students presenting different levels of abilities come to class, such as blind participants, marks on the colored cards can be easily inserted to allow identification and differentiation. The principle Differentiated \& Attractive guided the decision of how students' interest would be manifested. We decided to use a ballot box and cards with both the written word and an image representing the technology to favor students' autonomy: being able to recognize the technology by the image, they would not depend on someone else to complete the activity.

After this workshop, we identified the smartphone as the most common device, even though just a few students had one of their own. Their interests about it were photos, music, and phone calls. These results informed the following steps. Indeed, this first workshop was key for a comprehensive Step 1 as it was fully dedicated to promoting interaction between the participants and building a pleasant environment to explore and learn. All the information obtained from this workshop informed further cycles of our model from Step 1 to Step 3 in a constructive way.

Step 2 - create activities: As students revealed interest in taking pictures, we created an activity to help them with this purpose. Activity 04 - Training Photographers: the activity's goal was, all of us, together, create a list of instructions (algorithm) for taking a good picture and practice this algorithm on a smartphone. At this moment, as students were in the literacy process, it would not be suitable to involve written materials: the list should be simple for them to remember when practicing on the devices. The activity was described in detail and shared with all the researchers involved so everyone could be aware of what was going on. The activity was previously validated with the YAE teachers.

Step 3 - carry out activities: The taking pictures activity was conducted in the second workshop. In the introduction, we talked about the process of taking pictures with old devices. Many students had experience with that, and we dedicated some time to share their stories. Then, 
we guided the conversation, asking them for more precise instructions about how they used to take pictures. From what students said, we started to build our list of instructions about taking a good picture, pointing out some similarities with older devices, and adapting some instructions to the smartphone operation. A student told the group that, when she was a kid, taking pictures was like having a soda for Sunday's lunch: it had to be a special day for these things to happen and that now things changed. After this moment, we arranged the participants into three groups and practiced the algorithm to take pictures using the researchers' smartphones. As devices were different, we discussed the differences and similarities in the used smartphones (enhancing pattern recognition). All students had the opportunity to take pictures - Figure 4 presents three pictures taken by students.

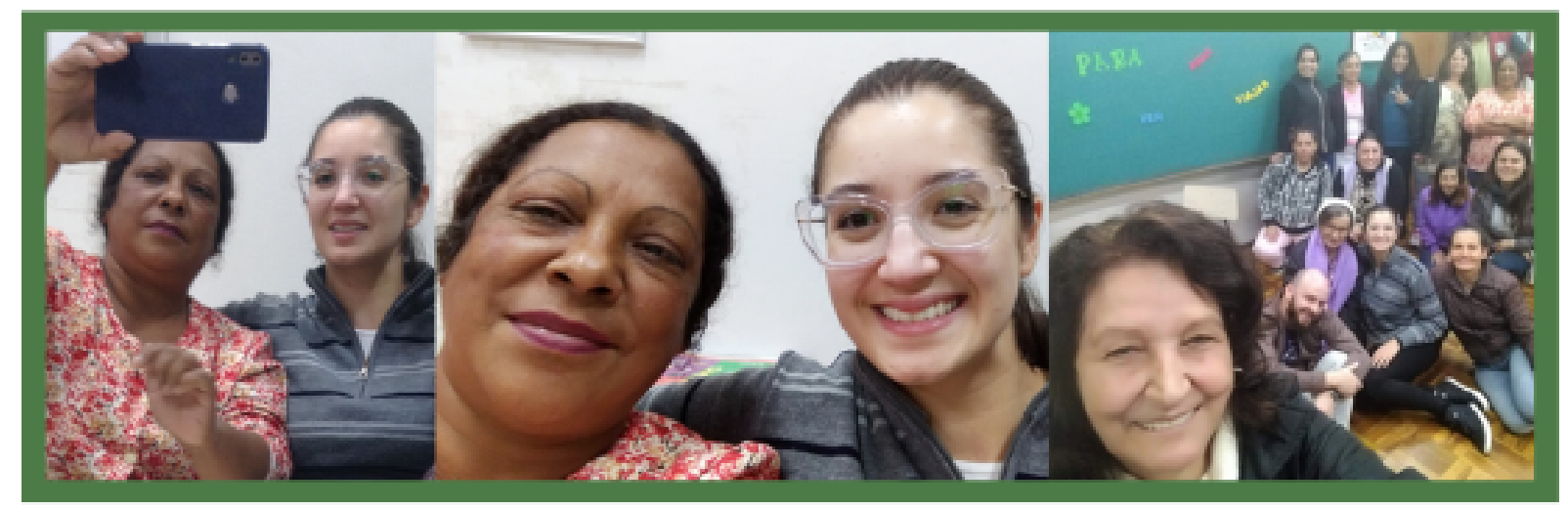

Figure 4: Pictures taken during the 2nd workshop.

As the activity was going on, many goals were achieved: participants described an algorithm to a specific goal and were able to practice with different smartphones - for most of them this was a new experience. Participants cited some benefits of the smartphone, for example, we do not need to wait for days to see the picture that was taken. They also recognized their contribution to the produced algorithm, demonstrating they do have useful experiences that can support the usage of technology.

New cycles: eight cycles were conducted from our first visit in the school to the last workshop. For each cycle, the knowledge and experience produced in the previous cycles were useful to inform the next ones. As another example, for the 7th cycle, we prepared a workshop to practice making calls via WhatsApp. The cycle was executed as follows:

Step 1 - get to know the students: In the previous workshops, we identified students having relatives living far away from them. The only way to talk to these relatives was through calls on WhatsApp, which they liked because they could talk and see each other. However, it became clear they had no experience in doing the calls on their own. So, every time they wanted to talk to a relative, they had to ask to use someone's smartphone and also ask the smartphone's owner to make the call for them. We saw this situation as an opportunity to explore, following the Socioculturally contextualized principle.

Step 2 - create activities: Activity 11 - Making phone calls. The goal was practicing video and audio calls on WhatsApp through the interpretation and execution of an algorithm. Once we designed this activity and described how it would work, paper materials were prepared to facilitate its conduction. We prepared prints of the WhatsApp Icon, (Figure 5 - A), and the "audio call" and 
"video call" buttons, right next to related objects they would recognize (Figure 5 - B and C).

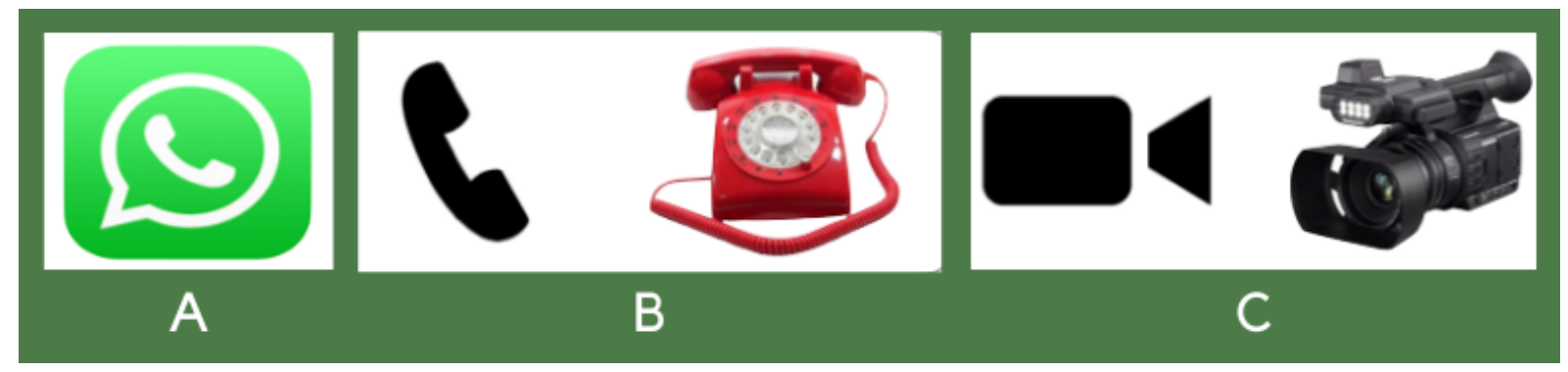

Figure 5: A - WhatsApp Icon, B - Audio call button, C - Video call button.

We also prepared real-size screenshots for the steps of making a call (Figure 6) to facilitate understanding, and also because students could use them to simulate and practice. This decision is especially important when there are no devices available for everyone to practice at the same time. Also, participants could draw and highlight something they would find necessary to learn and remember, and could also take the material if they want to practice more at home.

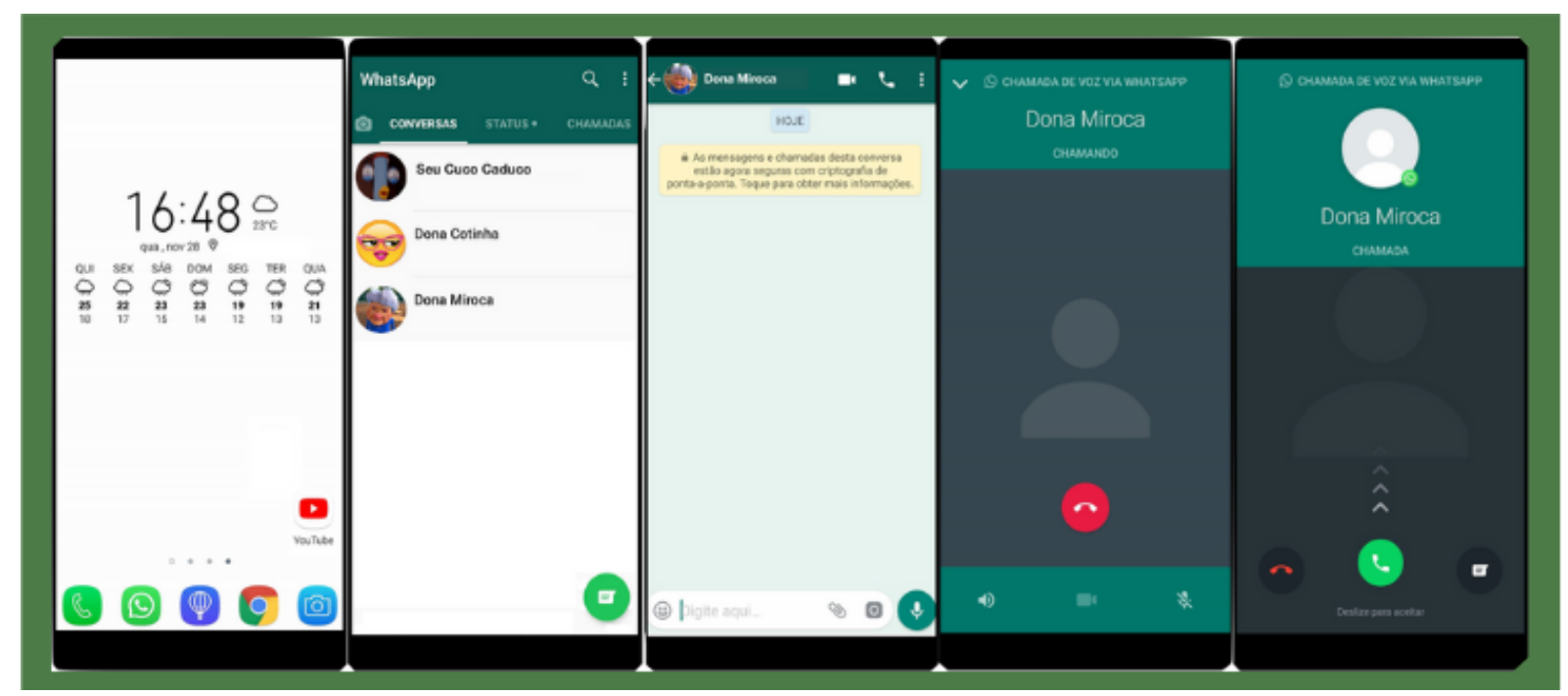

Figure 6: Real-size screenshots for the activity of making a call.

As another printed material, we prepared a pictorial algorithm (a kind of storyboard) about how to make a call (Figure 7). With the support of printed materials, students could simulate the process while waiting their turn to practice.

The Useful principle was considered as the activity's goal was to practice something relevant for their daily life. Therefore, knowing how to make phone calls would be immediately applicable, making them see how they are progressing. The Universal principle was considered by using paper material in large size, so seeing and handling would be facilitated. Self-contained was considered as the activity was designed to start and end in the same workshop, lasting less than 2 hours. We could have extended the practice and the exploration of the app to the following workshops, but it would take more time. If students attend only one of the workshops, maybe the knowledge created in a single workshop would not be enough to start practicing phone calls 
in their daily life. The trans-disciplinary principle was considered as CT abilities were practiced in different moments of the activity: pattern recognition was involved in analyzing the objects and the WhatsApp Icons, and in analyzing the printed and the smartphone screens (as they were slightly different). The Progressive principle was considered because we moved from practicing with description and simulation of steps (in the former activities) to practicing the interpretation and execution of sequences of steps, requiring a little more of the students.

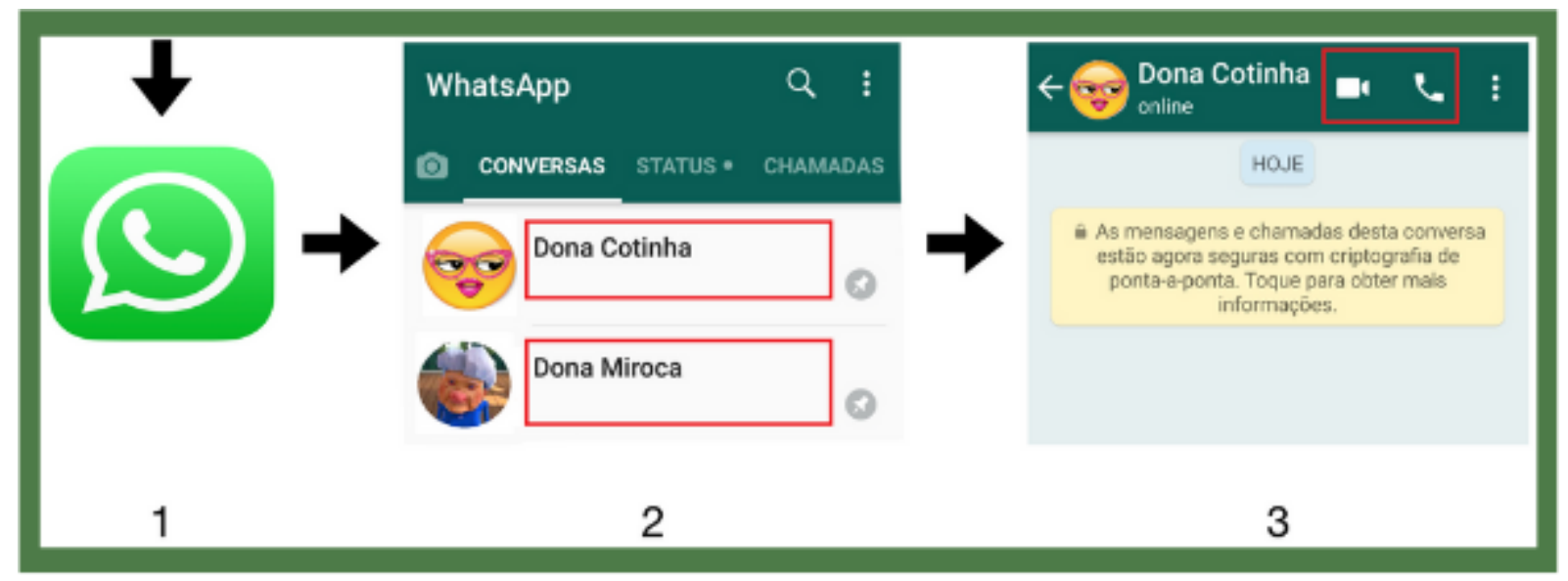

Figure 7: Pictorial algorithm about how to make a call.

Step 3 - carry out activities: By the seventh workshop, students were more comfortable in holding the smartphone and had practiced CT abilities in different contexts. We started the workshop with a moment to discuss the icons they would find when using WhatsApp. That was the moment we have chosen to enhance their former knowledge in the activity because the icons were related to objects they might know. In this conversation, we asked if they recognize those objects, if they have used them, what their function was, and what it means to have those objects as icons. We have spent some time discussing it and remembering related devices and objects. Figure 8 shows pictures from this workshop. Besides raising awareness about their knowledge about the topic, our goal was to promote a conversation about physical and digital objects and what they might mean, promoting understanding, not only memorization. After this moment, we presented the WhatsApp Icon and the "audio call" and "video call" buttons.

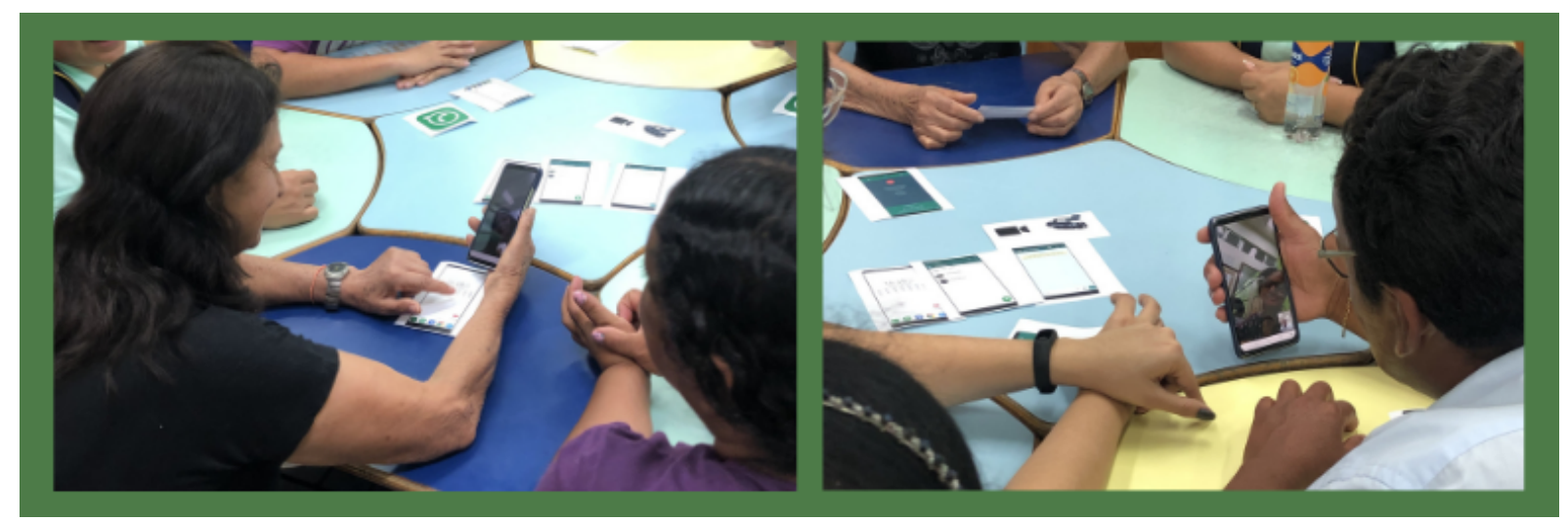

Figure 8: Pictures taken during the 7th workshop. 
We started the activity by giving the real-size screenshots to each student. After explaining each screen, the pictorial algorithm to make a video/audio call was provided too: their goal was to interpret and execute the algorithm. First, they should practice with the printed screens, and then with the real device. As there were only four smartphones, two by two, students were calling and answering calls from each other. As smartphones were different, we again discussed the differences and similarities among different operating systems and physical devices.

\section{Results \& Discussion}

After the 8 workshops involving many activities and technologies (Figure 9), observation from both teachers and researchers suggested a reduction in students' resistance to contact with technological devices, as well as an increase in the interest to learn more about technology. In the early workshops, only talking about technology seemed to make them feel uncomfortable. In the beginning, we were used to hear sentences like: "I will not be able to learn about it", and "my grandchild knows how to do all this, he is the one who should be here", suggesting a feeling of incapability. When using a smartphone, they were usually uncomfortable, hardly hold it with full hands. Instead, they tried to hold it with their fingertips, which could demonstrate resistance or insecurity about the device. As the workshops were taking place, commentaries of insecurity disappeared and, instead, students were getting engaged in the activities and having fun, elaborating and testing their solutions.

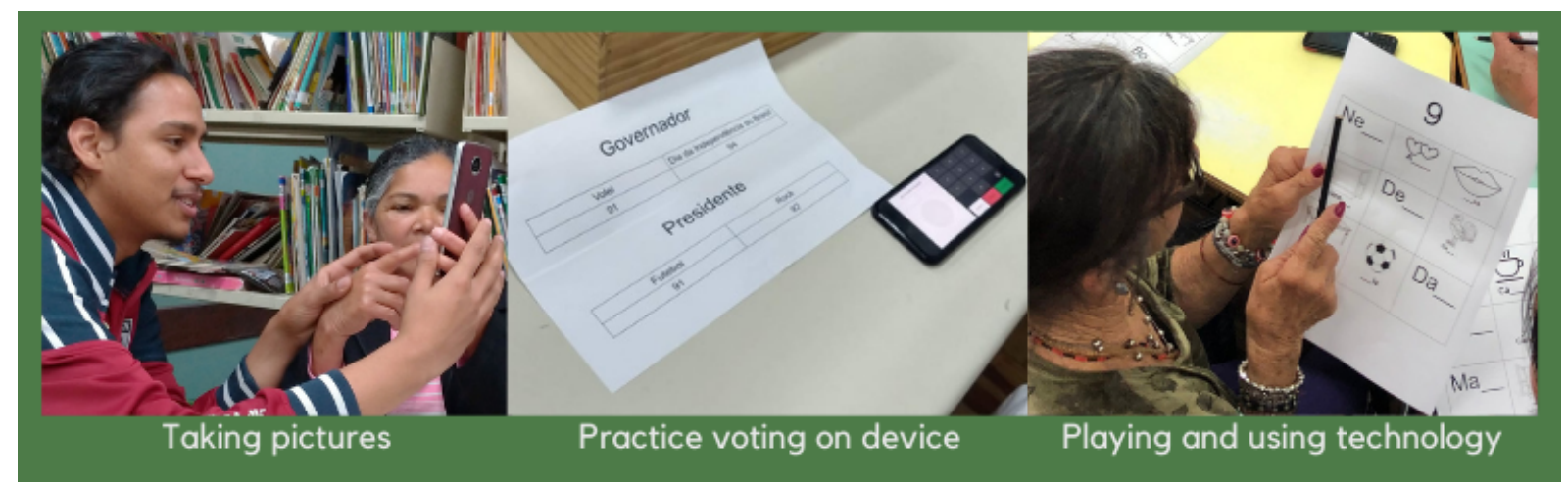

Figure 9: Pictures of workshops and activities during the initiative.

The participation on the workshops were voluntary. All the present students decided to participate, and they were always excited for the workshops. We consider that students' attendance in the workshops is a strong evidence of the reduction of internal barriers for their contact and use of technology and our success in making activities relevant for their life context.

The participants' answers to our questions about the workshops corroborate our perception of students' engagement and positive learning perception (using the cards presented in Figure 2). As Figure 10 - A shows, for their interest to learn more about technology we received 68 votes during the whole season, and the 68 were "Yes". Regarding their learning self-perception (Figure 10 - B), only asked in workshops that involved practical activities and content (from 2nd to 7th), from 64 votes, 57 were "I learned a lot", 6 were "I learned", 1 was "So so", and none was "I 
learned a little" or "I learned nothing". Based on these results, we consider that students were motivated and had an excellent perception of their learning progress.

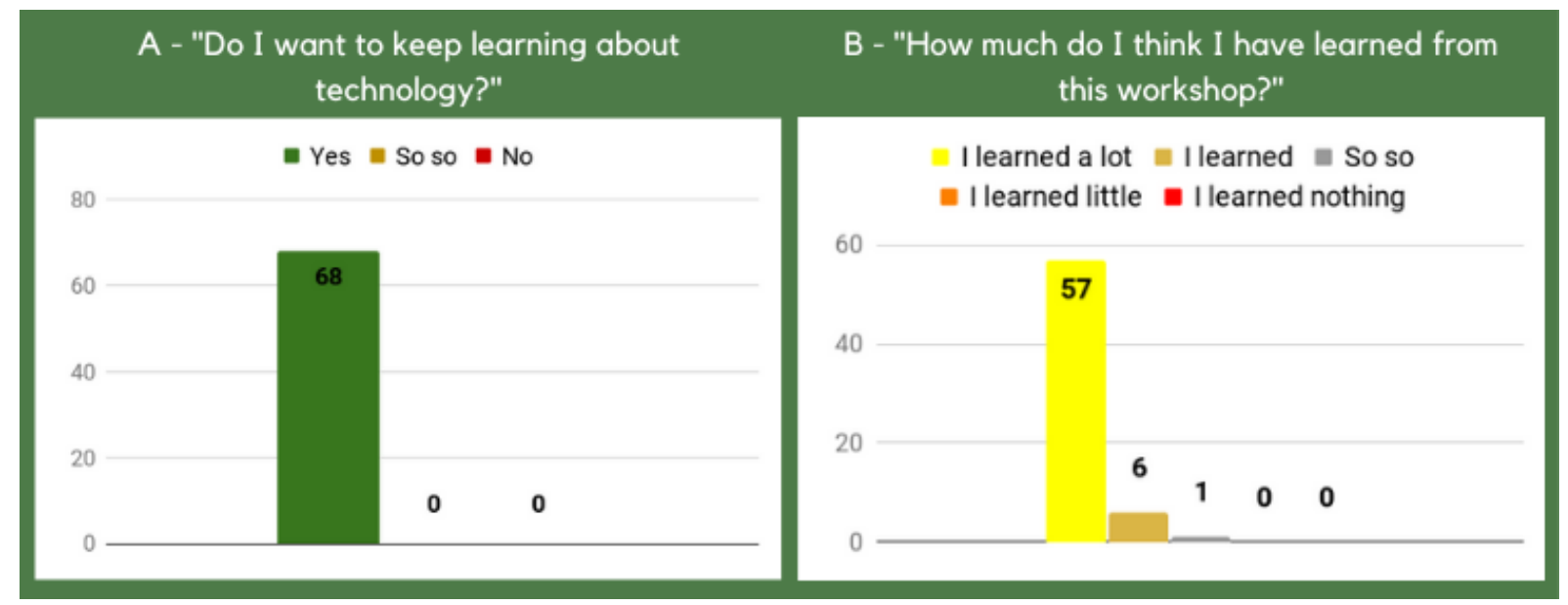

Figure 10: A - Results from students interest in learn more about technology, B - Results from students learning self-perception.

During the workshops, students always had many experiences and personal stories to share about the addressed topics, indicating that activities involved subjects meaningful to their lives. Teachers reported that students were using at home the knowledge they have created during the workshops, sharing their experiences with their colleagues. Taking pictures of their family's Sunday lunch or voting are a few examples of knowledge they have practiced in their own context. This feedback indicate that the workshops designed through the model involved contents from students' contexts and contributed to them.

Regarding CT and digital inclusion, the more they could complete the activities with technological devices, the more they seemed to feel part of a group, and the more they felt confident to share their - temporary - lack of ability for some tasks. In the third workshop, with a voting terminal prototype, we identified students around their sixties who had never voted via the voting terminal before because they could not have help while operating it. Many of them even described the act of voting as something bad or painful, based on their previous experiences with this technology. Together, we created an algorithm for the whole voting process, and as the discussion was going on, students realized they only did not know a few steps of the process and how to perform them on the voting terminal. Practicing CT abilities, such as problem decomposition, simulation, and algorithm, helped students perform a complete algorithm to vote in the voting terminal prototype. After this workshop, in October 2018, one student reported having voted for the very first time, offering evidence of reduction of rejection and fear of technology.

The ability to hold (and use) the smartphone was surprisingly improved as another evidence of a reduction in fear of technology. By the last activity involving the smartphone, students were asked to interpret and execute an algorithm based on the experience they had developed along the workshops. Some students (5 from the 12 present) were able to hold the smartphone and complete the activity without any help, only with the material and explanations provided at the beginning of the workshop. The other students completed the activity as well, with some help during the process - as was expected, and showed no concern or fear of doing something wrong. 
According to the teachers' feedback, after the workshops students started asking them for a list of instructions of what was expected to be done in the regular activities, claiming that when writing down, they would not forget anything and could consult if they needed to. We understand this as evidence that students comprehended the idea of an algorithm, some CT abilities' benefits, and have applied them in other contexts.

Regarding barrier reductions in contact and use of technology, a student said that when we invited her to the activities, she felt that she would not be able to participate and carry out any of the activities. However, when she took the first picture in the second workshop, she decided to keep learning about technology as long as she had the opportunity to do so. This student took several pictures of Christmas to show her teachers. Then, each change she makes in her garden, she photographs to show to her colleagues. Another student commented that she was able to talk to her grandson through a video call on WhatsApp, and she also took pictures of her family over the weekend: her relatives thought she would not be able to, but she did it and told us proudly: "They asked me where I had learned how to do it, and I told them I had learned at school!".

After a few months, teachers reported that students commented they now have or want to have a smartphone, and are looking forward to a new season of activities for using their own devices. As another positive evidence, in the following term after the workshops, students who had taken part in them were telling new students about what they have done and learned together, and have invited them to participate too. Indeed, when we got there for the second season of workshops in 2019, they were already waiting for us, and with many new doubts and topics they wanted to discuss.

These observations, together with the results students have achieved, corroborates that the practice of CT abilities helped to reduce the rejection and fear of technology and supported them in using technological devices. They also show that contextualizing the activities engaged students to participate and favored using the created knowledge in their lives.

Hence, we understand that practicing CT as a natural part of positive experiences and contextualized activities helps students to be curious and willing to explore new technology. This naturally helps them understand how technology works, the possibilities and restrictions on its use, how it should be used, and in what contexts it could be used. The more one comprehends these aspects, the more favored the interaction with technological devices tends to be. For people who are not used to use computing technology as part of their daily lives, practicing CT abilities can provide fundamental structures (i.e., mental models) to experience digital environments.

As a limitation, we have not compared the proposed model with other frameworks or materials. The study case was conducted as part of the construction process to refine the model. The case study showed that the model is feasible, applicable, and achieves the proposed purpose. Further applications are still needed to answer about its replication and effectiveness in different YAE contexts. A longitudinal case study is under development to further discuss it.

As the main threats to the validity of this research, we consider the researchers' bias when collecting data and misinterpreting the data. To mitigate the first threat, we invited more than one researcher to be the observer in classes; we transcribed what the students said and discussed the observations together after each workshop. To mitigate the misinterpretation, we discussed with the YAE teachers about students' behaviors and feelings about our initiative (opinions they might share in other moments or classes) and compared our results with the teachers' feedback. 
Based on the results discussed above, we consider that our Socially Aware Model for CT initiatives with YAE audience was helpful to plan and conduct workshops that achieved students' socio-cultural contexts, needs, and expectations, contributing to students' motivation to learn and their development in the usage of technology.

\section{Lessons Learned}

From the case study, we identified 17 lessons learned that can be useful to support and inspire further initiatives with the YAE audience. These lessons refer to different issues that must be taken into account when working in the YAE context.

Lesson 1. Introduce the project and the researchers: On the first day with YAE students, present the initiative and the goal to be achieved with them. This attitude contributes to set a trustful relationship with the students, who feel they are participants being heard and respected.

Lesson 2. Start with a pleasant activity: Especially at the very first workshop, propose a fun activity for everyone to feel comfortable with the group. During the first workshop, reinforce the idea that we are together: we have difficulties, some things to learn and to teach, fears and capacities, and we can study and experience together.

We suggest conducting an activity involving motor coordination as it helps to verify whether any student has movement limitations. This may require specific resources when carrying out further activities, so the sooner researchers are aware of these limitations, the better.

Lesson 3. Encourage informal moments for socialization: YAE students love to talk; they like to have attention, when someone asks about their day, their experiences, and stories. We think it is important that students share their impressions and experiences because: a) this indicates they are comfortable with us being part of their group (i.e., the researchers and other participants) and with the proposed activities; $b$ ) they feel more secure and confident to continue learning and asking questions; c) if they have some experience related to the workshop, that indicates a relevant topic is being addressed; d) it adds to the understanding about their context, bringing more aspects that can be explored in future workshops; and, e) it helps to know what they have taken from the previous workshops, whether they thought about the previous experiences, whether they applied their knowledge to other activities, etc.

Lesson 4. Have extra time for conducting activities: The desire students have to talk and socialize reduces the time available for activities. For example: if there is 1 hour for a class, plan 30 to 40 minutes of content and activities, and save at least 20 minutes for initial interaction and closing. This situation was observed throughout all the workshops.

Lesson 5. Be careful with questions asked to students: Even simple questions can make students feel uncomfortable. For example: In the first workshop, a student named 'Iolanda' introduced herself, and someone asked whether her name started with the letter I or Y, but she did not know how to answer as she still did not know how to write her name.

Additionally, when researchers do not know a conversation context or when students are talking about personal issues, avoid asking questions that encourage them to keep talking (e.g., "Are you serious?" or "Really?"). Students may feel encouraged to share embarrassing or contro- 
versial issues openly, talking about them or other people's lives.

Lesson 6. Do not hide students' difficulties and celebrate their achievements: Shame may be a reason for trying to hide something, either a mistake or a difficulty. By hiding or ignoring students' mistakes, we can give them the impression that they should be ashamed of them. The ideal is to openly talk about each of the issues discussed, without insisting to the point of being uncomfortable, but also without ignoring. Emphasize that the purpose of the activities is to learn and create an environment where everyone teaches and learns, including researchers and teachers. Each accomplishment should be celebrated as another step forward, never comparing students to each other, but highlighting the breakthroughs that each one has made in activities.

Lesson 7. Have more than one researcher in class: We recommend having at least three researchers/facilitators at each workshop: 1 . A facilitator to conduct the activities; 2. An observer to take notes and support the facilitator; 3 . Someone to practice with the students as a member of their group, experiencing the activities with the students. Moreover, sometimes dividing the group into smaller teams may be necessary, requiring a volunteer for each group to give them proper attention. Remember that students empathize in different ways with different people, so it is interesting to have more than one researcher in class. However, it is also important not to change the entire group of researchers/facilitators: at least two people must always be present.

Lesson 8. Researcher attitude: The researcher acting as the mediator/facilitator is there to facilitate and engage, creating a welcoming and open environment so everyone feels comfortable in sharing and learning together. If there are more people in class (e.g., regular teachers), everyone should participate in the activity. If possible, even the person who is eventually observing and taking notes should naturally engage in activities so that all people in the environment are engaged in the same dynamics and sharing experiences.

During our workshops, the second author and the YAE teachers took part in the activities with the students. More than promoting a sense of partnership by doing it together, students could see them trying, failing, trying again, and enjoying the experience. Doing things together breaks the distance between students and teachers/researchers as they see that everyone has something to learn and to teach.

Lesson 9. Small rewards: During the activities, it is positive to have small rewards/gifts, such as chocolates and candies, because it may turn the learning moment more enjoyable and students feel they are special. People tend to talk more openly and participate more comfortably when something favors the senses and the awareness of the moment experienced. Attention: consider items individually packed so that they can eat at the time they want, or even take it home; bring salty options too as students may have health issues like diabetes, and be careful with things that can be too hard to bite/chew.

Lesson 10. Take notes about students' comments: Students share a lot of what they do, difficulties they face, places they like to go, experiences they have, etc. This information is relevant input for better understanding their context. Sometimes, a comment or piece of information may not sound meaningful when it is shared, but it can make a difference in the near future or can even be used as an example or context for talking with them. Therefore, taking notes is important to remember what they share. Students like to be quoted, and they also remember a given situation when examples are being told. 
Lesson 11. Involve different aspects of students' context: Due to the age range allowed to attend YAE classes, having students between 16 and 70 years old in the same class is common. In these cases, finding an aspect of the students' context equally relevant to all of them can be a challenging task. Diversity is the key: try to involve various subjects from the students' context in the activities so that everyone can find some relevant issue.

Lesson 12. Produce written materials and illustrations in large size: As students may have visual or motor limitations, producing materials in large size facilitate their reading and recognition as well as handling.

Lesson 13. Use simple materials: Try to use the same materials the school usually provides to students, as prints, drawings, papers, etc. When introducing digital devices, be careful not to encourage the idea that it is something 'untouchable' because it can make students feel uncomfortable or afraid of using. Prepare the environment to offer spaces for using and experiencing devices and objects (e.g., a table where students can lay their materials). If some equipment requires too much attention to be manipulated or can easily break, maybe it should not be part of the initiative.

Lesson 14. Redundancy of information: Especially when involving students in the literacy process, present illustrations combined with written words (e.g., the word "phone" and a picture of a phone). This association facilitates understanding and helps students creating relationships between the word, it's representation, pronunciation, and meaning.

Lesson 15. Present several examples on the same topic: Because students come from quite different life situations and experiences, whenever possible, use several examples to explain each content. This can make that information 'accessible' to the largest number of students.

Lesson 16. Respect the pace of each student: Give students time to reflect on content and experiences, try, test new hypotheses, try again, and so on. When the group has students with different experiences and abilities, some may easily understand content and instructions, while others may require extra time. If there are students who have already gotten the things done, a viable alternative is to ask them to help their colleagues or show what they have managed to do - do not try to speed up the others. Offering additional activities to be performed and explored is also a good practice. This is one of the principles of our model and also appears in the lessons learned due to its importance.

Lesson 17. Progress constructively: In a workshop, create activities that favor the knowledge to be gradually improved, with every next activity involving a little bit more of their skills. Progressing from easier to more challenging tasks inside a specific workshop, as well as across the workshops, can favor a progressive dynamic where students experience and learn. We have found it beneficial to start with simple activities and then evolve into more elaborate activities; start with prototypes and unplugged activities and then evolve into the use of devices and systems.

\section{Conclusion}

Promoting CT to groups in vulnerable contexts is both a challenge and an opportunity for research and practice, especially considering all the barriers and difficulties people face and the potential CT has to support the solution of many problems. We argue that Computational Thinking skills 
have a direct relationship with inclusion and use of technologies: at the same time CT enhances the autonomy and appropriation of technologies, it is developed and improved with the results of an autonomous and positive experience. The key point for this relationship to occur and remain is how experiences are conducted. For the YAE this audience, learning how to use technology could be the opportunity to start acting in society.

In our research, we approached CT as a way to reduce people rejection and fear of technology and potentially foster digital inclusion. We consider that the practice with CT abilities can favor comprehension and autonomy for using computing technologies. This approach, however, cannot be detached from students' socio-cultural context, from the relevant aspects of their lives. Contributing to the CT literature, a Socially Aware Model was proposed to help planning and conducting CT initiatives with YAE students, context-sensitive to students' particularities. This model was applied and analyzed in a case study with YAE students in a public school.

Results from the case study suggest the model was helpful to support researchers when planning and conducting activities that matter to students, are useful for their lives, contributing to their motivation to learn more about technology. During the case study and the practice with CT, we observed a reduction in students' resistance to contact with computing technology, an increase in their interest to learn more about technology, and an excellent learning self-perception. Progress was observed and felt by everyone every day: from the very first class when they were not comfortable holding a smartphone, until the last class in which they were calling each other on smartphones by themselves and taking pictures of their houses to show to other students.

The case study led to a set of 12 activities, 9 principles to guide research and practice in the YAE contexts, and 17 lessons learned discussed with researchers and teachers. For this paper, we present the whole set of principles and lessons learned - not only regarding technology, as the way how the experiences are conducted is key to their success. The Socially Aware Model we present in this paper is a support towards understanding and conducting activities that make sense to YAE students. The CT abilities can enrich such activities, making them suitable to practice abilities that will be useful for students when understanding and using computing technologies.

Our model, its principles, and lessons learned are a basic material we suggest for CT teachers and researchers to know before getting into the YAE classroom. We hope to favor initiatives from the Computing field for addressing the YAE audience, helping researchers start planning their initiatives having a basic knowledge about the YAE characteristics.

As future research, advancing the theoretical ground is necessary. Applying the model to understand, plan and conduct activities in different contexts must be done to both refine the model and get evidence of its contributions and limitations. Longitudinal studies that allow accompanying students from different contexts and ages in the practice of CT initiatives are also welcome.

\section{Acknowledgments}

We dedicate this paper to students and teachers from the Rachel Mader Gonçalves school, especially teachers Luceli Rocio Cassilha Gabriel, Keila Rafaela Rezende Lima Gomes and Viviane Prás Galvão, and we thank them for the opportunity and partnership to work and learn with them. We also thank our colleagues from the IHC-UFPR Lab for their support during this project, es- 
pecially Deógenes da Silva Pereira Jr., Carolina Moreira Oliveira, Krissia Menezes, Bernardo Ferrari, and Ermelindo Schultz, because of their enormous contribution to imagine and develop this project. The authors thank the editors of RBIE for the invitation to publish this extended and revised version, and the anonymous reviewers who contributed to this research. Finally, we also thank the Julia S. B. Ortiz's Dissertation Defense Committee members: professors André Raabe, Clodis Boscarioli, Laura Garcia and Marcos Castilho, for the critical suggestions and appreciation of this research. This research was partially supported by CAPES - Financing Code 001.

\section{Extended Awarded Article}

This publication is an extended version of the best masters dissertation award winner in the Alexandre Direne Contest for Theses, Dissertations and Undergraduate Work in Computers in Education (CTD-IE 2020), entitled "Computational Thinking for Youth and Adults Education: Towards a Socially Aware Model”, DOI: 10.5753/cbie.wcbie.2020.52.

\section{References}

Baranauskas, M. C. C. (2014). Social awareness in HCI. Interactions, 21(4), 66-69. doi: $10.1145 / 2621933$ [GS Search]

Barr, V., \& Stephenson, C. (2011). Computational thinking to k-12: What is involved and what is the role of the computer science education community ? ACM Inroads, 2(1), 48-54. doi: 10.1145/1929887.1929905 [GS Search]

Best, J. W., \& Kahn, J. V. (2016). Research in Education. Pearson Education India. [GS Search]

Carbajal, M. L., \& Baranauskas, M. C. C. (2019). Involving users and creating symbols for tangible programming: A case study with TaPrEC. Journal on Computational Thinking (JCThink), 3(1), 65. doi: 10.14210/jcthink.v3.n1.p65 [GS Search]

Costa, B. V. B. (2014). Pensamento computacional na Educação de Jovens e Adultos: um estudo de caso utilizando dispositivos móveis. Monografia. Universidade de Brasília, Instituto de Exatas, Departamento de Ciência da Computação. Brasília/DF. [GS Search]

DiSalvo, B., Yip, J., Bonsignore, E., \& Carl, D. (2017). Participatory design for learning. Routledge. [GS Search].

Feitosa, S. C. S. (1999). Método Paulo Freire-Princípios e Práticas de uma Concepção Popular de Educação. Universidade de São Paulo - Faculdade de Educação. [GS Search].

Freire, P. (1997). Pedagogia da autonomia: Saberes necessários à prática educativa. Paz e Terra.

Li, Y., Schoenfeld, A. H., diSessa, A. A., Graesser, A. C., Benson, L. C., English, L. D., \& Duschl, R. A. (2020). Computational Thinking Is More about Thinking than Computing. Journal for STEM Education Research, 3, 1-18. doi: 10.1007/s41979-020-00030-2 [GS Search]

Mendoza, Y. L. M., \& Baranauskas, M. C. C. (2020). Evaluating the Socioenactive Experience with a Tangible Tabletop Installation: A Case Study. In Iberoamerican Workshop on Human-Computer Interaction (pp. 126-135). doi: 10.1007/978-3-030-66919-5_13 [GS Search]

Moreira, E. A., Dos Reis, J. C., \& Baranauskas, M. C. C. (2019). Artefatos Tangíveis e a Avaliação de Estados Afetivos por Crianças. Brazilian Journal of Computers in Education, 27(01), 58. doi: 10.5753/rbie.2019.27.01.58 [GS Search] 
Nardelli, E. (2019). Do we really need computational thinking? Communications of the ACM, 62(2), 32-35. doi: 10.1145/3231587 [GS Search]

Neri, M. (2009). Motivos da evasão escolar. Brasília: Fundação Getúlio Vargas, 1-34.

Nicastro, F., Baranauskas, M. C. C., \& da Silva Torres, R. (2018). A Methodology to Conduct Computational Thinking Activities in Children's Educational Context. In CSEDU (2) (pp. 309-316). doi: 10.5220/0006808803090316 [GS Search]

Ortiz, J. S. B. (2019). Pensamento Computacional e Educação de Jovens e Adultos: na direção de um modelo socialmente consciente. Master's thesis. Programa de Pós-Graduação em Informática - Universidade Federal do Paraná, UFPR. Curitiba/PR. [GS Search]

Ortiz, J. S. B., Oliveira, C. M., \& Pereira, R. (2019). Teaching computational thinking: are we considering students' socio-cultural context? Journal on Computational Thinking (JCThink), 3(1), 3-18. doi: 10.14210/jcthink.v3.n1.p3 [GS Search]

Ortiz, J. S. B., \& Pereira, R. (2019a). Atuando na Educação de Jovens e Adultos: nove princípios para guiar a prática. In Anais dos Workshops do III Congresso Brasileiro de Informática na Educação (WCBIE 2019) (Vol. 8, p. 437). BR. doi: 10.5753/cbie.wcbie.2019.437 [GS Search]

Ortiz, J. S. B., \& Pereira, R. (2019b). Ten years of initiatives to promote computational thinking: A systematic mapping study. Journal on Computational Thinking - (JCThink), 3(1), 95-110. doi: 10.14210/jcthink.v3.n1.p95 [GS Search]

Ortiz, J. S. B., \& Pereira, R. (2020). Computational Thinking for Youth and Adults Education: Towards a Socially Aware Model. In Anais dos Workshops do IX Congresso Brasileiro de Informática na Educação (pp. 52-61). doi: 10.5753/cbie.wcbie.2020.52 [GS Search]

Ortiz, J. S. B., \& Raabe, A. (2016). Pensamento computacional na educação de jovens e adultos: Lições aprendidas. In Anais dos Workshops do V Congresso Brasileiro de Informática na Educação (WCBIE 2016) (Vol. 5, p. 1087). doi: 10.5753/cbie.wcbie.2016.1087 [GS Search]

Panaggio, B. Z., Carbajal, M. L., \& Baranauskas, M. C. C. (2019). Programação Tangível no Mundo Físico: TaPrEC+ Sphero. Revista Brasileira de Informática na Educação, 27(03), 32-51. doi: 10.5753/rbie.2019.27.03.32 [GS Search]

Raabe, A. L. A., Brackmann, C. P., \& Campos, F. R. (2018). Currículo de referência em tecnologia e computação: da educação infantil ao ensino fundamental. Centro de Inovação para a Educação Básica - CIEB. [GS Search]

Schultz, E., Ortiz, J. S. B., García, L. S., \& Pereira, R. (2018). Teaching game design and basic computing concepts: a democratic experiment in a socioeconomically vulnerable community. In Anais do XXIX Simpósio Brasileiro de Informática na Educação (SBIE 2018) (Vol. 29, p. 1103). doi: 10.5753/cbie.sbie.2018.1103 [GS Search]

Sparling, J., \& Chong, I. (2011). Natural Observation (S. Goldstein \& J. A. Naglieri, Eds.). Springer US. doi: 10.1007/978-0-387-79061-9_1916 [GS Search]

Tissenbaum, M., Sheldon, J., \& Abelson, H. (2019). From computational thinking to computational action. Communications of the ACM, 62(3), 34-36. doi: 10.1145/3265747 [GS Search]

Vieira Pinto, A. (2013). Sete lições sobre educação de adultos. Edição 2013. Cortez.

Wing, J. M. (2006). Computational thinking. Communications of the ACM, 49(3), 33-35. doi: $10.1145 / 1118178.1118215$ [GS Search] 